\title{
Intellectual disability and the prison setting
}

\author{
V. Tort ${ }^{1}$, R. Dueñas ${ }^{1}$, E Vicens ${ }^{1}$, C Zabala ${ }^{2}$, M Martínez ${ }^{2}$, DM Romero ${ }^{2}$
}

${ }^{1}$ Parc Sanitari Sant Joan de Deu. Sant Boi de LLobregt (Barcelona)

${ }^{2}$ Facultad de Terapia Ocupacional, Logopedia y Enfermería de la UCLM. Talavera de la Reina (Toledo)

\begin{abstract}
Introduction: The prevalence of intellectual disability (ID) in the prison setting has scarcely been studied. Although some approximations or estimates regarding people with intellectual disabilities have been performed in Spain, there is little in the way of reliable data.

Objectives: 1) To determine the prevalence of ID in a sample population in the residential modules of a Spanish prison, 2) Obtain data on the prevalence of ID in prison psychiatric units and hospitals.

Methods: 1) A TONI II test was performed on a sub-sample $(\mathrm{n}=398)$ of a prevalence study in Spanish prisons ${ }^{33}$ to identify inmates with intellectual disabilities. 2) We reviewed the reports of the psychiatric department of Parc Sanitari Sant Joan de Deu to establish the diagnosis at discharge of patients with a primary diagnosis of intellectual disability 3) Data from the Directorate General of Prisons on the prevalence of ID in Prison Psychiatric Hospitals was reviewed.

Results: The data obtained from the TONI II test found $3.77 \%$ of the study population has an IQ below 70 , and $7.54 \%$ has a borderline IQ rate. Assessment of penitentiary psychiatric hospitalization data showed these figures to be higher.

Conclusions: The data from a Spanish prison population showed that ID levels were higher than those in the community, especially amongst prisoners requiring specialized psychiatric care. What is also evident is that adequate resources are required in prisons and in the community to provide better care for people with intellectual disabilities who are in the pathway of the criminal justice system.
\end{abstract}

Keywords: Prisons; Intellectual disability; Psyquiatry; Mental disorders; Mentally Ill Persons; Spain; Prevalence; Disabled Person.

Text received: $22-10-2014$

Text accepted: 12-08-2015

\section{INTRODUCTION}

In recent years there has been growing interest on people with intellectual disability (ID) and involved with the criminal justice system. For these people, the judicial process once accused of a criminal offence is particularly complicated. From the awareness of a determined behavior to the intricate legal jargon, sometimes the intellectually impaired are not able to understand their criminal position ${ }^{1,2}$. Once sentenced, they face different situations that range from a difficult adaptation to the peculiarities of the prison setting to probable victimization.

In a systematic revision ${ }^{3}$ a firm conclusion could not be reached on the prevalence of people with ID due to the heterogeneity of the samples, although the results suggest that between 0.5 and $1.5 \%$ of the inmates were diagnosed of ID $^{3}$. Søndenaa ${ }^{4}$ found a prevalence of $10.8 \%$ with IQ below 70 . The figures are especially alarming as far as significantly limited intellectual capacity (SLIC), with prevalence rates of $20.1 \%$. Up to $29.7 \%$ female inmates had ID in comparison with $20 \%$ of women with similar life conditions (socially deprived, in need of support by social services) and who had not been in prison ${ }^{5}$. In Spain, there has been a very significant increase in the number of people with ID reported to the Prison Administration between 2002 and 2007. From the 668 people identified in $2002(1.52 \%)$ it has risen up to 2323 in 2007 $(4.14 \%)^{6}$. The considerable need of inmates with learning difficulties in the United Kingdom have been addressed by the Bradley Report ${ }^{7}$, which recommends an early detection and assessment of the needs as to determine where it would be more appropriate for these patients to be treated ${ }^{8}$.

People with ID are more prone to suffering from mental health issues, uncovered care needs and recidivism ${ }^{9}, 10$. Mental disorders can present differently 
without first order symptoms. In the main, more behavior disorders are spotted, which although not thoroughly evaluated, can include antisocial patterns. Cooper ${ }^{11}$ describes a prevalence of mental disorders of around 30 to $40 \%$, behavior disorders being the more prevalent. Mental health issues were associated to life events, female inmates, less capacities, more medical consultation, and smoking, the lack of significant physical disabilities, unemployment, communication issues, epilepsy, hearing difficulties and previous institutionalization ${ }^{11}$. In his study, Dias ${ }^{12}$ concluded high prevalence rates of psychiatric co morbidity (37.2\%): anxiety depression and substance dependence being the most common and an increased use of antipsychotic drugs. Hassiotis ${ }^{8}$ described a psychosis rate of up to twice as higher as among other inmates. As for drug abuse, ID inmates were frequent users of cannabis. We must further consider that cannabis dependence mediates the strong association between psychosis and ID. This data supports the high prevalence rates concluded among the imprisoned population, cannabis being the most common drug ${ }^{13}$. Bhandari ${ }^{14}$ describes a prevalence of drug abuse of $28.0 \%$.

Sixty percent female inmates with ID have reported being sexually abused and $40 \%$ physically abused ${ }^{15,16}$. Among this sub-population of inmates self-injury behaviors are more common as well as physical violence to others and the presence of personality disorders ${ }^{15,17}$. As for self-inujury behaviors there is a lack of information according to most of the studies carried on people with $\mathrm{ID}^{18}$. The study by Duperouzel and Fish ${ }^{19}$ underlined the importance of the emotional aspects of their lives and how self-destructive behaviors entail a coping strategy. Hassiotis found twice as many suicide attempts and higher rates of self-destruction behaviors among these inmates ${ }^{8}$.

Attention Deficit Hyperactivity Disorder (ADHD) has been associated both to the prison system and to intellectual disabilities yet it has only recently begun to be assessed in imprisoned patients.

In the 1930's higher prevalence rates of ID were described among the imprisoned population in comparison with studies carried on later ${ }^{17}$. In the United Kingdom, most of the inmates have lower IQ than the average and more learning difficulties (Math and Language $)^{20}$. In the United States, the prevalence of ID in prison is around 3\%, alike the general population, while in the United Kingdom it seems to be under $1 \%$, a fact which is probably due to potential non-prison derivation from police custody, as well as to the fact that people with ID are more frequently sentenced to alternative penal measures. Their high vulnerability is based on the following facts: the misunderstanding of their rights, suggestibility, and acquiescence, difficulty regarding complicated questions and taking the wrong decisions while in custody. Yet it is not clear whether people with ID have more probabilities of committing crimes, since the leading risk factors for delinquency such as poverty, social deprivation, young age and being male are risk factor for people with ID too, as well as the lack of resources to become an integral part of society ${ }^{21,22}$. With regard to the types of crimes committed there is an excess of crimes against other people while there seem not to be any difference regarding sexual offences. Anyway, sexual immaturity and the lack of experience seem to be the main factors, the majority being minor crimes. These patients have usually a background of social or psychological deprivation, behavior issues at school, poor control of impulses, low self-esteem and an impaired capacity to establish standardized sexual or personal relationships. As far as pyromania, there seems to be an increase although without statistical significance. Often, starting a fire is an expression of distress, anger or vengeance ${ }^{23}$. As for crimes against public health, there would be a significant reduction (see Table 1).

Within correctional facilities, people with ID would be left out of specific treatments for violent and sexual crimes, and substance abuse. The reasons reported by professionals would be the difficulties to understand to sentence, erratic monitoring and poor take-up. Non implementation of these measures entails reduced therapeutic output, leave permits and penitentiary advantages. They would also face difficulties in accessing working reinsertion programs and being assigned to activities in prison wards. All these situations would ultimately jeopardize rehabilitation and resocialization. As for the efficacy of treatments, recidivism rates are lower in those who have undergone treatment. As for the duration of treatment, those who have been under treatment for over two years had improved output in comparison with those who underwent treatment for shorter periods of time $^{23}$. With regard to crimes, especially regarding sexual offences, the approach for inmates with ID reveal very low recidivism rates, even in community treatments ${ }^{24}$. Access to substance abuse programs for people with ID is usually limited and non-adapted to their needs, a fact which entails a lack of essential treatment upon release and which clearly affects criminal recidivism. Few inmates with ID received specific treatment for drug dependence and even fewer followed an educational program ${ }^{8}$. 
Table 1. Comparison of crimes committed by inmates with ID and the rest of inmates.

\begin{tabular}{lccc}
\hline \multicolumn{1}{c}{ Crime $^{*}$} & $\begin{array}{c}\text { Ministry of the Interior } \\
\text { Intellectual Disabilities }\end{array}$ & Department of Justice & PRECA study \\
\hline Homicide & $9.39 \%$ & $7.5 \%$ & $10 \%$ \\
\hline Sexual Offences & $5.98 \%$ & $6.06 \%$ & $7.7 \%$ \\
\hline Robbery & $53.20 \%$ & $44.8 \%$ & $54.8 \%$ \\
\hline Public Health & $8.20 \%$ & $27.15 \%$ & $23 \%$ \\
\hline Breach & $1.84 \%$ & - & $5 \%$ \\
\hline Injury & $5.98 \%$ & $4.14 \%$ & $9.5 \%$ \\
\hline Arson & $1.34 \%$ & - & $0.4 \%$ \\
\hline Coercion & $2.12 \%$ & - & $3.4 \%$ \\
\hline Other & $11.85 \%$ & - & $17.9 \%$ \\
\hline
\end{tabular}

*Ranged in comparable groups for better understanding, 2007 data.

The POMONA II study (on medical co morbidity) revealed an increased physical morbidity in people with ID. They are characterized by low participation in prevention and health promotion programs, a higher number of hospital admissions and poor use of emergency services ${ }^{25}$. A high prevalence of epilepsy can affect behavior in different ways such as: 1) irritability and/or aggressive episodes prior to seizures and 2) confusion episodes which can trigger aggressive behaviors. In primary care often diagnostic overshadowing (the attribution of symptoms to underlying ID) can be found. Mental disorders are widely under-diagnosed since clinicians tend to think that people with ID are prone to emotional issues, being bad-tempered and mobile ${ }^{25}$. The presence of inmates with ID confronts the progress achieved by the collective in social integration with the exclusion entailed by the correctional system $^{26}$. The main complaints by inmates with ID are usually related with the following aspects: difficulties with peers leading to social isolation, inappropriate sexual behavior, and difficulties in daily activities, mood changes or aggressive behaviors and issues with standardized social development and establishing an independent life. Many new inmates are not properly diagnosed of ID and sometimes it can only be a clinical impression. Rarely is IQ assessed by means of scales. On the sole basis of clinical impression we should be aware that there are other conditions which can interfere with educational or working performance ${ }^{26}$.
The study's endpoints are the following:

1) To determine the prevalence of intellectual disabilities in a sample of Spanish imprisoned population hosted in residential modules.

2) To obtain data on the prevalence of intellectual disabilities in units and prison psychiatric hospitals.

\section{MATERIAL AND METHODS}

The methodology used has been broadly discussed in the previous article on the PRECA study ${ }^{27}$. This is a cross-sectional descriptive epidemiological study carried out by means of a personal interview to the broader and more representative sample of imprisoned population of age hosted in correctional facilities in Madrid, Cataluña and Aragon.

Sample: 750 inmates were interviewed, equally distributed between the three autonomous communities by means of a list provided by each facility using a stratified random sampling technique as of an index date (Marc 20 $0^{\text {th }}$ 2007). Out of the 783 eligible male inmates invited to participate, $708(90.3 \%)$ agreed to do so and were interviewed and 76 refused to take part. Finally, out of the 708 participant inmates, 235 were hosted in facilities in Madrid, 222 in Cataluña and 250 in Aragon. The collection of data was carried out between April 2007 and June 2008.

Social, demographic, criminal, environmental and clinical variables as well as variables on quality of life, 
social impact and use of services were obtained. As for the collection of the aforementioned social, demographical, healthcare, criminal and penitentiary variables a structured interview was used.

For the clinical assessment, the SCID1 ${ }^{28}$ was administered, an interview protocol for DSM-IV Axis I Disorders by following a structured interview model and the International Personality Disorder Examination (IPDE) ${ }^{29}$. The recommendations by Alvaro-Brun were followed in administering the questionnaire ${ }^{30}$. Finally, for the evaluation of intellectual disabilities the TONI- $2^{31}$ test was administered: Test of Non Verbal Intelligence, a language-free measure of abstract problem-solving ability. This was chosen due to the high prevalence of immigrant population among inmates. We believed that a test free of cultural and learning influences could better detect the level of intelligence among this group of inmates. TONI-2 was administered to a sample of 398 inmates.

To determine quality of life, EuroQol-5D (EQ5D) questionnaire was used, a standardized instrument for use as a measure of quality of life with items grouped in two main measures: physical and mental health. With regard to the evaluation of social climate, the Prison social environment scale was used.

Statistical Data Analysis: through SPSS version 11.5 software (SPSS, Inc., Chicago, IL, USA). This study only includes a percentage description of TONI-2 scores.

This project was approved by the Clinical Research Ethics Committees of Sant Joan de Deu and Gol I Gorina and authorized by corresponding prison administrations both in Cataluña and the rest of Spain. This study has received a grant by the Agency for Healthcare Research, Carlos III Health Institute of the Spanish Ministry of Health and Consumer Affairs (FIS PI052517).

Data regarding the prevalence of ID in psychiatric units in Spanish prisons was collected from published data by the General Directorate of Penitentiary Institutions ${ }^{6}$ and that regarding psychiatric facilities in Cataluña was obtained from 2010 and 2011 Annual Healthcare Reports from the Department of Prison Psychiatry of Parc Sanitari Sant Joan de Deu, the Prison Psychiatric Hospital Unit of Brians I (Barcelona) and the Polyvalent Psychiatry Unit of Quatre Camins (Barcelona).

\section{RESULTS}

It is worth underlining that we have found a prevalence of $3.77 \%$ for IQ under 70 among inmates to
Table 2: Intelligence Quotient Scores (PRECA study).

\begin{tabular}{lcc}
\hline $\begin{array}{c}\text { Intelligence Quotient Score } \\
\text { (TONI II) }\end{array}$ & Total & $\%$ \\
\hline $61-69$ & 15 & 3.77 \\
\hline $70-79$ & 30 & 7.54 \\
\hline $80-84$ & 24 & 6.03 \\
\hline $85-89$ & 22 & 5.53 \\
\hline $90-94$ & 28 & 7.03 \\
\hline $95-99$ & 30 & 7.53 \\
\hline $100-104$ & 40 & 10.05 \\
\hline $105-109$ & 53 & 13.32 \\
\hline $110-114$ & 54 & 13.57 \\
\hline $115-119$ & 55 & 13.82 \\
\hline $120-124$ & 21 & 5.28 \\
\hline $125-129$ & 14 & 3.52 \\
\hline $130-134$ & 7 & 1.76 \\
\hline $135-139$ & 4 & 1 \\
\hline 140 & 1 & 0.25 \\
\hline TOTAL & 398 & 100 \\
\hline
\end{tabular}

whom the TONI-2 test was administered (n: 398) (see Table 2). When we further consider individuals with borderline intelligence the prevalence rises to $11 \%$. These figures reveal the importance of the issue in the prison.

Data described in Figures 1 and 2 depict diagnoses upon release in the Prison Psychiatric Hospital Unit of Brians I and the Psychiatric Infirmary Unit of Quatre Camins. This corresponds to inmates who were mainly diagnosed of mental retardation but whose imprisonment was not related to other psychotic disorders and additionally presented mental retardation. Imprisonment of patients with mental retardation probably is related to unspecified behavior disorders which do not correspond to clear psychiatric symptoms.

Both the data corresponding to the Prison Psychiatric Hospital Unit of Brians I (see Figure 1) and those from the Psychiatric Nursing Unit of Quatre Camins (see Figure 2) show prevalence rates of around $10 \%$. 


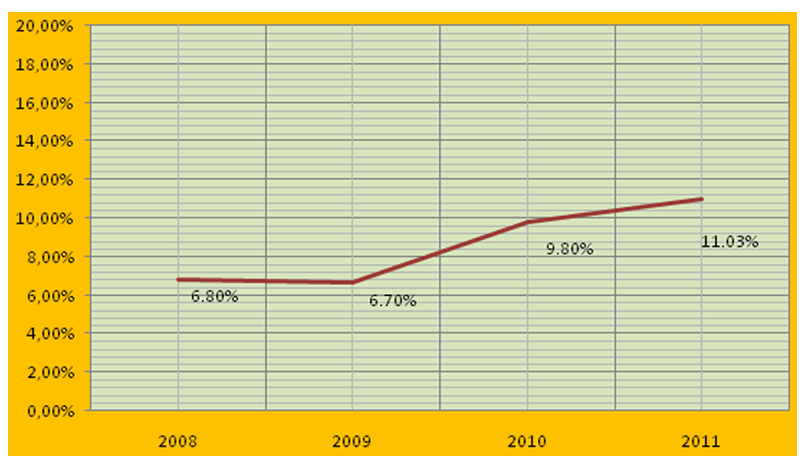

Figure 1. Percentage of inmates with mental retardation (UHPP).

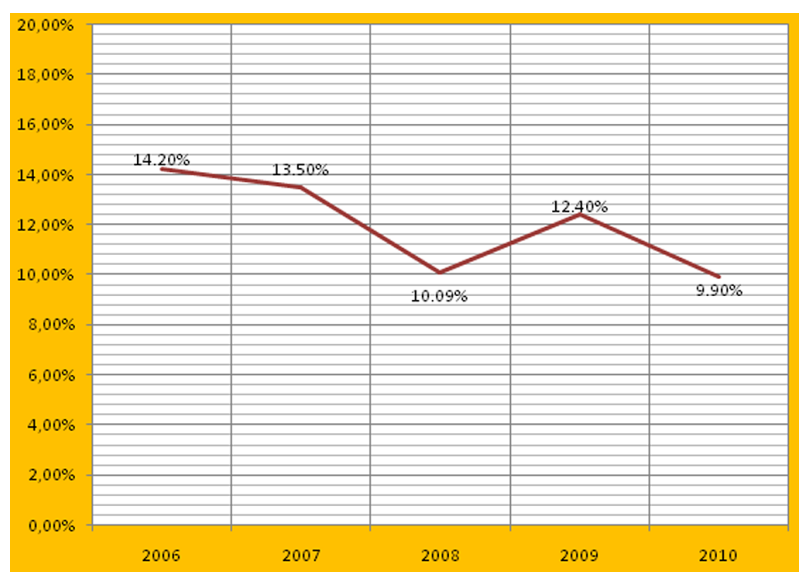

Figure 2. Percentage of inmates with mental retardation (UPPQC).

Table 3 shows the percentage of inmates who have been diagnosed with mental disorders in prison psychiatric hospitals depending from the General Secretariat of Penitentiary Institutions, where a high prevalence of intellectual disability has also been spotted (around 7\% in the 2007 revision).

\section{DISCUSSION}

The prevalence of ID $(3.77 \%)$ concluded in our study complies with other scientific literature ${ }^{8}$, and is higher than that described in the general population (around 1\%). Furthermore, if we consider patients admitted to prison psychiatric facilities this figure rises by 2 to 3 times. By including only the main diagnosis these figures include a wider number of patients with ID since in some cases they would be considered as co-morbid diagnoses. Psychiatric admissions are more related to adaptive behavioral alterations than to other associated psychiatric symptoms. Within the criminal climate, it is worth noting the prevalence of co-morbid mental disorders in which we could con-
Table 3. Distribution of the population hosted in Prison Psychiatric Hospitals according to psychiatric diagnosis. Comparison 2002-2007 (percentages).

\begin{tabular}{lcc}
\hline & Year 2002 & Year 2007 \\
\hline Psychotic disorders & 57.87 & 50.45 \\
\hline Substance abuse & 7.87 & 25.05 \\
\hline Personality disorders & 13.43 & 10.91 \\
\hline Mental retardation & 7.87 & 6.80 \\
\hline Affective disorders & 6.02 & 3.76 \\
\hline Other & 2.08 & 2.86 \\
\hline Pending diagnosis & 4.86 & 0.00 \\
\hline Total & 100.00 & 100.00 \\
\hline
\end{tabular}

Source: Compiled by authors based on data from the General Directorate of Penitentiary Institutions.

sider dual or even triple pathology when we consider ID, mental disorder and substance abuse.

Hassiotis $^{8}$ described how inmates with ID were more probably young females from ethnic minorities. A high percentage has been under the assistance of local authorities as children and has been admitted to psychiatric hospitals. Furthermore they are under preventive measures or have shorter sentences. Despite a similar percentage of inmates with ID having a court order for psychiatric treatment, they were placed in infirmaries instead of ordinary prison wards. Although they had a similar number of visits by family and friends, these inmates reported a lack of social support. With regard to their perception of their degree of health, near $12.6 \%$ of inmates with ID reported poor levels, compared with $6.3 \%$ among the rest of inmates. Moreover, they did not receive appropriate assistance for their mental health needs ${ }^{10,12}$.

According to Murphy ${ }^{21}$, although risk assessment and management are emerging issues regarding people with ID, it is more and more necessary to implement this in the approach of inmates with ID. Hence, Fitzgerald $^{32}$ has determined the predictive efficacy of VRAG and HCR-20 in inmates with ID. Moreover, potential victimization leading to physical, emotional and sexual abuse could entail behavioral alterations and thus, disciplinary sanctions ${ }^{21}$. De Beer's study ${ }^{33}$, carried out on 200 patients from a low-security unit, revealed that one third could have been hosted in community residence facilities.

From the criminal point of view, there are no specific programs aimed at individuals with ID. It has 
been established that the implementation of specific cognitive behavioral therapies within prisons improves their prognosis ${ }^{21}$. Moreover, access to rehabilitation programs focusing on employment (social and working reinsertion), specific programs (drugs, violent or sexual offences) and other rehabilitation activities would make their stay in prison shorter.

The lack of forensic community services approaching mental pathologies leads to difficulties regarding the awareness by community services, and hence the delay in their rehabilitation. In some cases, difficult externalization would be related to both social and healthcare stigmatization, which does not take over cases from prison. Therefore, a joint approach by community forensic teams and community services would improve how these patients are dealt with in the community ${ }^{16}$. The association between mental disorder and ID leads to delayed and unspecialized access to psychiatric services. The lack of proper training among healthcare professionals is a fact. It would be essential to implement early detection of cases in juvenile justice services, where the approach is more educational and where preventive politics could be developed aimed at recidivism and social rehabilitation of teenagers with $\mathrm{ID}^{8}$. Furthermore, it is not uncommon that individuals from deprived groups, such as illegal immigrants would be first diagnosed in prison due to a lack of prior detection. According to Hayes ${ }^{34}$, five main issues require immediate attention in the future:

1. Uncertainty regarding the actual number of offenders with ID;

2. Lack of identification of ID among offenders;

3. Lack of knowledge on ID among professionals from the criminal system;

4. Lack of alternative non-custodial resources

5. Shortage of community and prison services ${ }^{34}$.

A report by the Andalusian Ombudsman already offered a series of recommendations regarding these lines of action.

The lack on studies addressing ID among inmates make it difficult for both healthcare and criminal approaches leading to a reduction of recidivism and stigmatization as well as improving quality of life. This is especially alarming regarding female inmates with ID, who are prone to social exclusion, sexual physical and emotional abuse and higher rates of mental disorder. Studies should reach conclusions allowing for a more individualized approach ${ }^{34}$.

Recently, growing awareness by Penitentiary Institutions and different associations on the provision of care to people with ID who are deprived of their liberty has lead to consider the need for special tra- ining and coordination between the criminal, police and prison systems to implement specialized social, educational and mental health resources. Efforts should be made to develop specific resources for offenders with ID ${ }^{35}$. In 2006, the Spanish Confederation of Organizations in favor of People with Intellectual Disability published an "Intervention Guidelines for people with ID affected by the criminal system", within the Rehabilitation Activities Program for convicts and ex-convicts with ID. In Cataluña, the Accepta program has been assisting people with ID who have problems with justice for many years now. The program's most notable objectives include avoiding the imprisonment of people with ID where possible, promoting their release where possible and improving their quality of life when release is not possible.

Ever since 2004, the Prison Administration has a specialized resource for people with ID which works as a social-healthcare facility, alike Occupational or Day Centers ${ }^{6,36}$. Although this is a first step towards more appropriate assistance to people with ID it is still insufficient for the comprehensive care that should be provided in prisons. Recently, a new resource was implemented in the prison of Quatre Camins, a Specialized Care Department hosting inmates with ID. On the other hand, specialized care provided by collaborating entities is not homogeneous throughout the country, where the degree of external resources varies widely. The provision of care in prisons does not count upon clear and specific programs.

It is compulsory that a coordinated strategy be implemented to face the complex needs of these inmates. It should include, for example, safe housing, programs addressing the improvement of daily life skills and appropriate health care including psychiatric monitoring and substance abuse programs. These needs call for inter-ministry cooperation and long term commitment. This should be accompanied by improved training of professionals at all levels: criminal and penitentiary and non-custodial alternative measures. The fact that offenders with ID do not access appropriate services that could prevent criminal conduct entails consequences for the individuals themselves, their families and society as a whole. For committed professionals both from the criminal system and specialized services, the difficulties to offer basic and simple services for these people are frustrating and daunting. Generally the community suffers from a social ethical and economical point of view ${ }^{33}$. Social and healthcare needs of people with ID in prison highlights the need for proactive appropriate and specific services and for prevention politics together with the coordination between the involved systems ${ }^{22}$. 
Among the limitations of our study it is worth noting that we excluded female, underage, senior and preventive inmates and hence, our conclusions cannot be extrapolated to these groups. The importance of our study is the prevalence of ID among a sample of inmates convicted in Spanish prisons. The high prevalence is significant for the implementation and improvement of care for these people as well as for the importance of effective community assistance that will avoid imprisonment or re-imprisonment.

\section{CORRESPONDENCE}

Vicente Tort Herrando

CP Quatre Camins

Carretera Masnou a Granollers, km 13

08430 La Roca del Vallès (Barcelona)

\section{BIBLIOGRAPHICAL REFERENCE}

1. Jones G, Talbot J. No One Knows: The bewildering passage of offenders with learning disability and learning difficulty through the criminal justice system. Crim Behav Ment Health. 2010; 20 (1): 1-7.

2. Talbot J, Riley C. No One Knows: offenders with learning difficulties and learning disabilities. $\mathrm{Br} \mathrm{J}$ of Learn Disabil. 2007; 35: 154-61.

3. Fazel S, Xenitidis K, Powell J. The prevalence of intellectual disabilities among 12000 prisonersA systematic review. Int J Law Psychiatry. 2008; 31 (4): 369-73.

4. Søndenaa E, Rasmussen K, Palmstierna T, Nøttestad J. The prevalence and nature of ID in Norwegian prisons. J Intellect Disabil Res. 2008; 52 (12): 1129-37.

5. Lewis K, Hayes SC. Intellectual functioning of woman ex-prisoners . Aust J Forensic Sci. 1998; 30: 19-28.

6. Huete A, Diaz E. Las personas con discapacidad intelectual en el medio penitenciario en España. Madrid: Cinca; 2008.

7. The Bradley Report. Lord Bradley's Review of People with Mental Health Problems or Learning Disablities in the Criminal Justice System [Internet]. London: Department of Health; 2009 [cited 2014 Dec 22]. Available from: http: //www. revolving-doors.org.uk/documents/lord-bradleys-review/

8. Hassiotis A, Gazizova D, Akinionu L, Bebbington P, Meltzer H, Strydom A. Psychiatric mor- bidity in prisoners with intellectual disabilities: analysis of prison survey data for England and Wales. BJP 2011, 199: 156-7.

9. Dias S, Ware S, Kinner S, Lennox N. Physical health outcomes in prisoners with intellectual disability: a cross-sectional study. J Intellect Disabil Research. 2013; 57 (12): 1191-6.

10. Vinkers D, Hoek H, Rinne T. Psychiatric morbidity in prisoners with intellectual disabilities. $\mathrm{Br} \mathrm{J}$ Psychiatry. 2011; 199, 512-9.

11. Cooper SA, Smiley E, Morrison J, Williamson A, Allan L. Mental ill-health in adults with intellectual disabilities: prevalence and associated factors. Br J Psychiatry. 2007; 190: 27-35.

12. Dias S, Ware RS, Kinner SA, Lennox NG. Co-occurring mental disorder and intellectual disability in a large sample of Australian prisoners. J Appl Res Intellect Disabil. 2013; 26 (5): 384-93.

13. Vicens E, Tort V, Dueñas RM, Muro A, Pérez Arnau FA, Arroyo-Cobo JM, et al. The prevalence of mental disorders in Spanish prisons. Crim Behav Ment Health. 2011; 21 (5): 321-32

14. Bhandari A, Van Dooren K, Eastgage G, Lennox $\mathrm{N}$ y Kinner SA. Comparison of social circumstances, substance use and substance- related harm in soon-to-be- released prisoners with and without intellectual disability. J Intellect Disabil Res. 2015: 59 (6): 571-9.

15. Alexander RT, Piachaud J, Gangadharan SK. Women with intellectual disability who have offended. J Intellect Disabil Research. 2005; 49: 635.

16. Lindsay W, Carson D, O'Brien G, Holland AJ, Johnston S, Taylor JL, et al. The relationship between assessed risk and service security level for offenders with intellectual disability. J Forensic Psychiatry \& Psychology. 2010; 21 (4): 537-48.

17. Holland T. Forensic Psychiatry and learning disability. In: Russell O, editor. Seminars in The Psychiatry of the Learning Disabilities. London: The Royal College of Psychiatrists. Gaskell; 1997. p. 259-73.

18. Brown J, Beail N. Self-Harm Among People with Intellectual Disabilities Living in Secure Service Provision: A Qualitative Exploration. J Appl Res Intellect Disabil. 2009; 22: 503-13.

19. Duperouzel H, Fish R. Hurting No-One Else's Body but Your Own: People with Intellectual Disability Who Self Injure in a Forensic Service. J Appl Res Intellect Disabil. 2010; 23, 606-15.

20. Xenitidis K, Fotiadou M, Glynis M. People with Intellectual Disabilities in Prison. En Wilson S, Cumming I editors. Psychiatry in Prisons. A 
Comprehensive Handbook. London: Jessica Kingsley Publishers; 2010. p. 107-24.

21. Murphy G, Mason J. People with intellectual disabilities who are at risk of offending. En: Nick Bouras and Geraldine Holt editors. Psychiatric and Behavioural Disorders in Intellectual and Developmental Disabilities. Cambridge: Cambridge University Press; 2007. p. 173-20

22. Ramos C. Las personas con discapacidad intelectual en el sistema penal penitenciario. ¿Un fracaso de las políticas de inclusión? Rev Inter de Org. 2013; (11): 15-35.

23. Tewari S. Intellectual disability and the law. En: Roy A, Roy M and Clarke D, editors. The Psychiatry of the Intellectual Disability. United Kingdom: Radcliffe Publishing limited. 2006. p. 133-152.

24. Nezu CM, Nezu AM, Klein TM, Clair M. Sexual offending behavior. En: Jacobson JW, Mulick JA, Rojahn J. Handbook of Intellectual and Developmental Disabilities. New York: Springer Publisher; 2007.p. 635-56.

25. Martínez-Leal R, Salvador-Carulla L, Gutiérrez-Colosía MR, Nadal M, Novell-Alsina R, Martorell A, et al. La salud en personas con discapacidad intelectual en España: estudio europeo POMONA-II. Rev Neurol 2011; 53 (7): 406-14.

26. Lorenzo J, Ramos C. Personas con diversidad intelectual en prisión. Desafíos para el Trabajo Social. Rev Inter Trab Soc y Bienes. 2014; (3) 167-72.

27. Vicens-Pons E and PRECA Group. Aproximación a la Metodología para el estudio de los trastornos mentales en población penitenciaria. El estudio PRECA. Rev Esp San Penit. 2009; 11: 17-25.

28. First MB, Spitzer RL, Gibbon M, William JB. Guía del usuario para la Entrevista Clínica Es- tructurada para los Trastornos del Eje 1 del DSMIV. Versión Clínica: SCID-I. Barcelona: Masson; 1999.

29. López-Ibor J, Pérez-Urdaniz A, Rubio V. Examen Internacional de los Trastornos de Personalidad . Módulo DSM-IV. Versión española. Organización Mundial de la Salud. Madrid. Meditor; 1996

30. Álvaro-Brun E, Vegue Gonzalez M. Trastornos de personalidad en prisión: Una cuestión compleja. Rev Esp Sanid Penit. 2008; 10: 29-30.

31. Brown L, Sherbenou RJ, Johnsen SK. Test de inteligencia no verbal: Apreciación de la habilidad cognitiva $\sin$ influencia del lenguaje. Madrid: TEA; 1995.

32. Fitzgerald S, Gray NS, Alexander RT, Bagshaw R, Chesterman P, Huckle P, et al. Predicting institutional violence in offenders with intellectual disabilities: the predictive efficacy of the VRAG and the HCR-20. J Appl Res Intellect Disabil. 2013; 26 (5): 394-403.

33. Beer De D, Spiller MJ, Pickard M, Gravestock S, Mcgovern P, Leese M, et al. Low secure units: Factors predicting delayed discharge. J Forensic Psychiatry \& Psychology. 2005; 16 (4): 621-37.

34. Hayes S. Missing out: offenders with learning disabilities and the criminal justice system. $\mathrm{Br} \mathrm{J}$ Learn Disabil. 2007; 35, 146-53.

35. Las personas con discapacidad intelectual y sistema penal. Balance y conclusiones de las jornadas, mayo 2011. Valladolid: FEAPS Castilla y Leon; 2012.

36. Sanz B, Roca M. Intervención penitenciaria con discapacitados intelectuales. El modulo de discapacitados del CP Segovia. Dirección General de Instituciones Penitenciarias. Ministerio del Interior. Madrid: Gobierno de España; 2009. 